\title{
A mixed approach for studying effectual entrepreneurial opportunities: development and appli- cation to Tunisian context
}

\author{
Faiez Ghorbel $^{\mathrm{a}^{*}}$, Wafik Hachicha ${ }^{\mathrm{b}, \mathrm{c}}$ and Younes Boujelbène ${ }^{\mathrm{d}}$
}

\begin{abstract}
${ }^{a}$ Department of Management, Faculty of Economics and Management of Sfax (FSEGS), Road of aeroport km 4, Sfax, 3018, University of Sfax, Tunisia

${ }^{b}$ Department of Industrial Management, Higher Institute of Industrial Management of Sfax (ISGIS), Road of Tunis km 10.5, PO Box 1164, 3021 Sfax, Tunisia

${ }^{c}$ Unit of Mechanic, Modeling and Production (U2MP), Engineering School of Sfax, Tunisia, University of Sfax, Tunisia ${ }^{d}$ Department of Quantitative methods, Faculty of Economics and Management of Sfax (FSEGS), University of Sfax, Tunisia

C H R O N I C L E

Article history:

Received: February 1, 2016

Received in revised format: April

16, 2017

Accepted: June 6, 2017

Available online:

June 6, 2017

Keywords:

Effectuation

Entrepreneurial opportunities

MICMAC method

Artificial Neural Network

\section{A B S T R A C T}

The aim of this paper is to propose a combined approach for studying entrepreneurial opportunities based on effectual variables. The proposed mixed approach is carried out in three phases. First, entrepreneur's effectuation variables are selected via a cognitive map and MICMAC method. Second, a Neural Network (ANN)-based model is performed to highlight the emergence of potential entrepreneur's conception which rely on effectuation key variables with survival and performance. Finally, ANN model is applied based on effectuation variables. Indeed, many confirmations and interesting findings have been concluded. The results of the proposed approach are essential to understand Tunisian entrepreneur's thinking and acting in entrepreneurship process. We make enrichments to the way of theorizing and practicing entrepreneurship, avoiding the idea of mythic entrepreneur.
\end{abstract}

Tunisia

\section{Introduction}

Entrepreneurial activity represents one of the major engines of economic growth. The core of entrepreneurship research is entrepreneurial opportunities creation, and identification studies in a real context. Understanding entrepreneurial thinking is imperative to understand the essence of entrepreneurship and how it emerges and evolves. This is especially true if we wish to move from descriptive research to theory-driven research. For example, if we wish to argue intelligently about whether entrepreneurial opportunities are "discovered" or if they are "created", theory is crucial. In this context, Sarasvathy $(2001,2008)$ advanced modeling of the entrepreneurial process by describing two distinct approaches to entrepreneurial activities: causation and effectuation. The causation approach, which is the classical one to explain previous literature studies, is consistent with planned strategy approaches, including 
such activities as opportunity recognition and business plan development. The planning and analysis required by causation approaches assume conditions in which the distribution of outcomes in a group is predictable through calculation or statistical inference. However, effectuation processes are consistent with emergent strategy and include a selection of alternatives based on loss affordability, flexibility, and expertise. Indeed, there is no feasible way to calculate an expected return for a given course of action. Thus, instead of analyzing alternatives and selecting the one with the highest expected return, the entrepreneur selects alternatives based on loss affordability (Chandler et al., 2011).

Obstruction for any nascent entrepreneur is the good idea (Silberzahn, 2013). The entrepreneurial community shares custom requirement of a good idea to undertake. In this context, a project is viable only if it is based on a satisfactory viable opportunity, a need in a marketplace, and accompaniment following to characteristics of the created project (business plan). For researchers in effectuation "reality" has another face. What effectuation suggests is the understanding of how entrepreneurs think and act. The entrepreneur does not develop a business plan; he builds it over the road. He does not conduct market studies as he seeks building strategic partnerships (Silberzahn, 2013). The entrepreneur relies on the available resources to create an entrepreneurial effect. Each effect, created, allows welcoming new relational, informational and personal resources. In other words, the entrepreneur maintains flexibility, utilizes experimentation, and seeks to exert control over the future by making alliances with, and getting pre-commitments from, potential suppliers, competitors, and customers (Sarasvathy \& Venkataraman, 2011).

Consequently, effectuation approach is a fertile logic in its unity because it includes several variables and dimensions that allow its understanding as a shared logic by entrepreneurs in creating their new firms. Numerous effectuation approaches are applied mainly in USA and Germany. In general, they focalized to some of effectuation principles and variables separately, but little with all of effectuation variables. To fill this gap, the aim of this paper is to propose a mixed qualitative and quantitative method, for studying entrepreneurial opportunities based on effectual variables. In fact, a mono-method study which uses only one type of method, one quantitative or one qualitative may cannot provide this goal. On the one hand, in qualitative research, the central questions are usually concise, open-ended questions that begin with "what", "why", or "how" to suggest an exploration and understanding of the central phenomenon (Creswell et al., 2003). On the other hand, quantitative studies are more appropriate to ask "how many", "how often" by studying causal relationships between variables. Quantitative research is very useful for establishing cause-and-effect relationships and for making generalizations about populations.

There are many mixed research studies that were developed in literature. It is better to divide these studies into two main categories of application: Sequential application such as in (Fuellhart \& Glasmeier, 2003) and (Rosa \& Dawson 2006), Simultaneous application such as in (Bertolini \& Giovannetti, 2006) and (Parrilli, 2009). For more details about mixed methods studies, reader can consult the good survey paper of Molina-Azorín et al. (2012), which presents a methodological review of the use of mixed methods studies in entrepreneurship. The proposed sequential mixed methods research is based on cognitive map and MICMAC method as qualitative methods and Artificial Neural Network as a quantitative method. Cognitive map is used to identify entrepreneur's variables. MICMAC method is applied to prioritize investigation's variables. The ANN methodology is performed to highlight the emergence of potential entrepreneur's conception. As a validation purpose, the proposed approach is applied to a virgin context like the country of Tunisia.

The rest of this paper is organized as following: Section 2 presents effectuation principles and the differences between causal logic and effectual logic. Section 3 presents a literature overview of entrepreneurial opportunities research. The aim of this section is to position the proposed approach over other literature research. Section 4 presents theoretical background which concerns cognitive map, MICMAC method and ANN. Literature overview related to each technique and method is also presented. Section 
5 describes the flow chart of the proposed procedure methodology. Section 6 presents in detail the Tunisian context and the analysis phases of the proposed approach. Finally, section 7 contains conclusions and perspectives for future research.

\section{Effectuation theory}

\subsection{Causal logic and effectual logic}

The key distinction in literature consecrated to effectuation is the different starting point in the entrepreneurial process. This distinction is based on the causal and the effectual model. Sarasvathy argues that the causation model starts with goals as a gathered, thus the basic decision for that model is on what means should be accumulated to achieve these goals. In effectuation context, entrepreneur starts with means and focuses on the decision of what effect can be created using these means (Kraaijenbrink, 2012). Like the experimental logic in science, effectual logic is actionable as it consists of mechanisms that specify how to work with readily available means to co-create local transformations through selfselected stakeholder commitments (Sarasvathy \& Venkataraman, 2011).

Causal problems are problems of decision; effectual problems are problems of design (Sarasvathy, 2008). In her groundbreaking article, Sarasvathy (2001) discusses causation and effectuation as different approaches to the venture creation process. We call the expert frame 'effectual' because it proceed outward from mean and cause to new effects and unanticipated ends (Dew et al. 2009). Sarasvathy compares and contrasts causation and effectuation models by applying the analogy of a chef assigned to the task of cooking dinner. In the causal case, the chef selects a menu, comes up with good recipes for each item on the menu, shops for necessary ingredients, arranges proper implements and appliances, and then cooks the meal. As indicated in Fig. 1, the causal process starts with selecting a menu as the goal and finding effective ways to achieve the goal whereas in the effectual case, the chef starts with looking through the kitchen cupboards for ingredients and utensils, then designs possible menus based on those ingredients and utensils. In fact, the menu often emerges while preparing the meal. The effectual chef starts with a given kitchen, and designs possible, sometimes unintended, even entirely original meals with its contents (Sarasvathy, 2008). The theoretical bases of effectuation are based on five principles and dynamic cycle (Read et al. 2011).

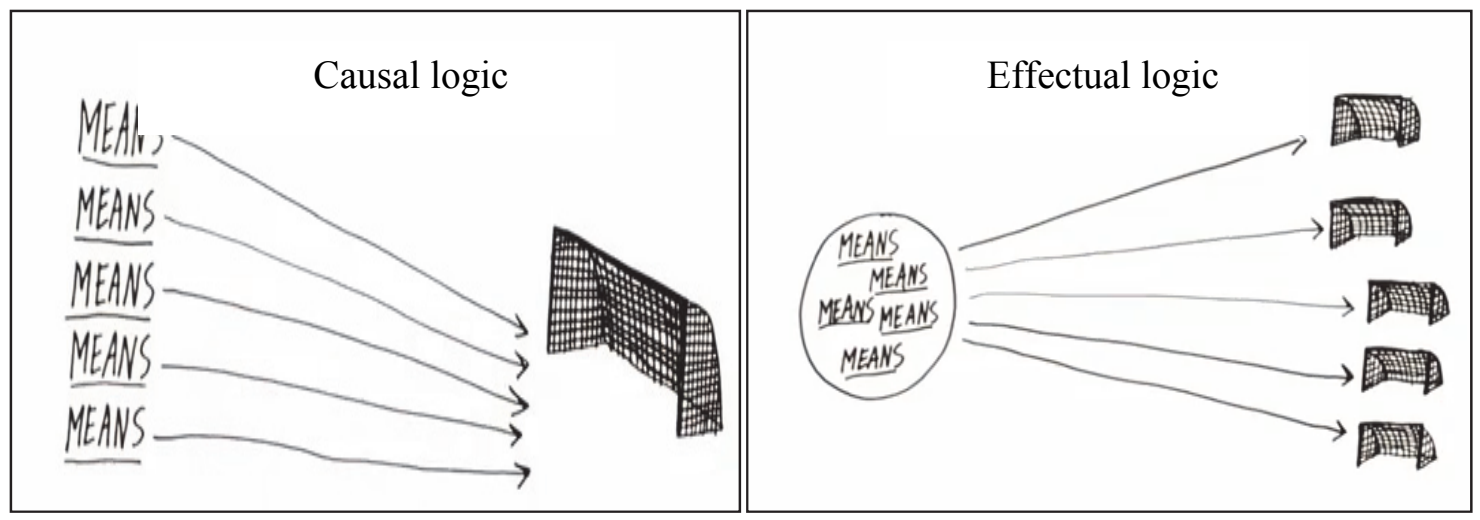

Fig. 1. Causal logic Vs effectual logic

\subsection{Effectuation principles and variables}

Effectuation is an oriented action. The effectual entrepreneur starts with the available means. Those means are considered as the bird in hand. This principle includes: who I am, what I know, and whom I 
know. Then, the entrepreneurs imagine possibilities that originate from their available means. In addition, effectual entrepreneurs set what they can afford to lose at each step. Therefore the entrepreneur tries to introduce partnership with self-selecting stakeholders. Partnership is essential for entrepreneur to interpret news and surprises as potential signs to create opportunity and market. Finally, entrepreneur controls his environment to cope with uncertainty influence. The observer of all those ingredients form the dynamic effectual cycle notes this finding: don't wait for opportunity but create it.

Effectuation principles are the foundation of entrepreneurial action. Theoretically, effectuation is noted by pioneers as oriented action. Saras Sarasvathy, highlights five principles used by expert entrepreneurs in their decision. Those principles are: (1) bird in hand, (2) the affordable loss, (3) crazy patchwork, (4) the lemonade and (5) pilot in the plane.

In effectuation logic entrepreneurs start with their means which can be grouped in three categories: who I am (personality), what I know (expertise), who I know (social network). Base on the combination between these means entrepreneurs imagine possibilities and make action (Read et al., 2011). For the second principle "affordable loss", entrepreneurs base their approach on cost control rather than on estimable incomes. The idea is the following: By the commitment in an entrepreneurial project, it is easy to limit its involvement in terms of costs. Affordable loss drives entrepreneur's decisions to an appropriate start-up. In this case, prediction is rejected from entrepreneur's action (Silberzahn, 2013). Effectual process does not evolve without the selection and the commitment of different stakeholders (Dew et al., 2007). Crazy patchwork principle emanate from this idea. The chain of commitments launched at the start of the venture has important impacts. It increases available means for entrepreneurs and supports them in an emerging approach (Read et al., 2011).

In addition to the previous point, the project goals are also identified with the stakeholders who are involved in. This, naturally, does not mean that you have to change your plans to any customer commitment (Sarasvathy, 2008). The effectuation is the movement from a logic of prediction (try to predict the market) to a control logic (invent it). The control logic also means that in the entrepreneurial process, it is the action that is preferred for analysis. The action is source of learning but also a way for environmental change. Action is a source of novelty (Wiltbank et al., 2009).

\section{Literature overview of entrepreneurial opportunities research}

Several literature studies from different contexts and research objectives have tried to understand the entrepreneurial economy by studying the determinants of the success of new venture. During the 1980's and 1999's, some of these studies have tied psychological traits of entrepreneurs with their firm success, but they did not seem to lead anywhere (Gartner, 1988). Some others have identified that entrepreneurs were also found to range all over the risk-performance spectrum (Palish \& Bagby, 1995). On the other hand, economic studies have theorized that entrepreneurial expertise was nothing but a statistical artifact. During the 2000's, studies in entrepreneurial activities research can be grouped in two mains approaches: causation and effectuation. This classification is based on how to argue intelligently about whether entrepreneurial opportunities are "discovered" or if they are "created". Consequently, it is better to present the literature overview of entrepreneurial opportunities research, according this classification.

\subsection{Literature based-causal logic}

On the one hand, the entrepreneurial opportunity is the center of gravity of the majority of research by studying the variables that allow the identification and exploitation or the creation of opportunities. Begin with the approach of the discovery of opportunities; Shane and Venkataraman (2000) explain the importance of prior opportunities identification and the cognitive proprieties to evaluate it. Accord- 
ing to Shane (2000), entrepreneurs discover opportunities that are related to information that they posses. In others conception the social network was an important element to study opportunities. In the conception of Sarah Jack (2005), Jack and Anderson (2002) the social network is a decisive variable of opportunity recognized and exploitation. Shane and Khurna (2003) suggest that career (experience) mechanism link individual level process to firm foundation. In Lumpkin and Lichtenstein (2005) conception opportunity is cognitive process of recognizing an idea and transforming an idea into a business concept.

\subsection{Literature based-effectual logic}

On the other hand, research of entrepreneurial opportunities such as in Hanssen et al. (2011), Alvarez and Barney (2010) note that the opportunity are registered in the creation approach. This approach is the core study of our paper. Cognition in effectual conception is the pillar of reflection and studying opportunities.

If we take the key elements of the entrepreneurial process with an effectual regard we find that the starting point of the project is very different. The key of the effectual logic is uncertainty (Sarasvathy, 2008; Read et al., 2008; Ghorbel \& Boujelbène, 2012, 2013). In uncertainty context possibilities are constructed with stakeholders with creativity and fusion between analyze and action. Uncertainty doesn't have any importance without opportunity emergence and viability. In the original conception of effectuation theory entrepreneurial opportunity, firm and market are social construction (Venkataraman \& Sarasvathy, 2011). Based on the available means, entrepreneurs take action following the specifics situation (Sarasvathy, 2008). He enters in interaction/ negotiation with stakeholders (Dew el al., 2009) in order to engage and accumulate new resources and expertise to her firm. The whole resources and expertise are the base of new goals. Entrepreneurs are the pilot of the effectual cycle they control their trajectory and decide to watch the environment not for what it is, but for what it could be (Read et al., 2011).

\section{Theoretical background and review}

The proposed sequential mixed approach is based on cognitive map and MICMAC method as qualitative methods and Artificial Neural Network as a quantitative method. Cognitive map is used to identify entrepreneur's variables. MICMAC method is applied to prioritize these variables. The ANN methodology is performed to highlight the emergence of potential entrepreneur's conception. In this section, we present the theoretical basis and a brief overview by interconnecting the exploited methods and entrepreneurship research.

\subsection{Cognitive maps}

The label "cognitive maps" has been used for several decades. It is originated from the ideas of Tolman (1948) who wished to develop an alternative to the stimulus-response model of man. The cognitive maps represent a map which is a model of cognition (thinking model). Then, Robert Axelrod (1976) applied cognitive maps in the 1970's to represent social scientific knowledge. Cognitive maps facilitate documentary coding and symbolic representations construction.

Literature researches have used cognitive maps in entrepreneurship to explain the nature of entrepreneurial thinking. In fact, research into entrepreneurial cognition offers a way to explore the reality of entrepreneur thinking in an entrepreneurial context. Indeed, understanding the cognitive infrastructure supports entrepreneurial activities research and gives us more strong perspectives to foster entrepreneurship. So we can understand how entrepreneurs deal with their entrepreneurial opportunities (Krueger, 2003). 
There are many technics which are available for performing cognitive maps such as SODA (Strategic Options Diagnostic Analysis), Grid Systematic Exploration (GSE), etc. These technics aim to reconstruct, from answers extracted from guided interviews with entrepreneurs, a cognitive representation of their reflections about causes and consequences of a particular context. An advantage of cognitive mapping technics (simply asking someone what he thinks) is the representation of entrepreneurs thinking and acting.

Mapping technics use different methods to elicit key concepts and relationships from an entrepreneur and then to build a map from this entrepreneur. There are two main procedures to construct a map for a group. This is important because representations which are shared by many entrepreneurs offer real possibilities to explain the nature of entrepreneurial opportunities. The procedure consists on combining maps from different entrepreneurs which are studied in a composite map that introduces representations of a specific group of entrepreneurs (Eden, 1992). The procedure is based on structuring tools such as MICMAC method.

\subsection{MICMAC method}

The MICMAC method is refers to their French acronym (Matrice d'Impacts Croisés Multiplication Appliquée á un Classement). MICMAC method is a structural analysis tools. The target of this tool is to identify the principal elements (variables) and then to determine the interactive influence between the selected variables. MICMAC method includes three successive phases: creating an inventory of variables, describing the relationships between the variables, and then identifying key variables. There are various structuring tools available in literature. Lendaris (1980) provides a list of nine structuring tools and compares them on the basis of a number of characteristics. We listed ISM, MICMAC, ELECTRE, SPIN, and IMPACT.

In this paper, we have chosen MICMAC method. MICMAC tool is more sophisticated and it is flexible to application in entrepreneurship research. This method is most commonly used in literature and let use subjective data. MICMAC method was initially developed by Duperrin and Godet (1973) for studying the diffusion of impacts. The developed hierarchies are constructed on the basis of influence and interaction between variables extracted from a specific subject of study. MICMAC method is a structural analysis tool which describes a system using a matrix which links the different variables of the system. This method identifies the main variables that are both influential and dependent. This finding is essential to the evolution of the system. MICMAC method approves that the cross impact matrix has already been filled. A suitable set of impact variables is already chosen. The direct impact strength of each impact variable is the criterion of codification in MICMAC tool and it has been classified by this way: 0 (no impact), 1 (little impact), 2 (medium impact), or 3 (strong impact).

The number of investigation studies in entrepreneurship using structural methods like MICMAC method are not frequent. In fact, MICMAC method is used essentially to study entrepreneur's cognitive representation by identifying the key factors of entrepreneurial activity's reflection. For instance, Omri and Frikha (2012a, 2012b) have used MICMAC method to identify the key factors of entrepreneurial opportunities identification. They have selected the cognitive dominant variables that are decisive in access to external financing. Khiari et al. (2011) have demonstrated, through MICMAC, that the definition of new technology for firm's innovation performance requires the reviewing of the analytic framework commonly used to understand entrepreneurial performance phenomenon. Moreover, Bootz and Monti (2008) have used a prospective research to give a prospect for professionals to conceive and manage approaches fitting the organization's needs. 


\subsection{Artificial Neural Network}

Artificial intelligence is the description given to the field of computer science exploited in the construction of programs that tends to imitate human intelligence. ANN is a kind of artificial intelligence tools increasingly used in solving problems with extreme difficult or complex analytical solutions. ANNs are composed of interconnected, usually adaptive elements, which are intended to respond to stimulus in a manner not unlike the human nervous system. Perhaps the most attractive property of these structures is the ability to learn associations between and patterns within data. The teaching procedure commonly consists of repeatedly presenting known input and output patterns to the system as it restructures itself to recreate the patterns. There are several important resulting attributes. First, it is not necessary to develop difficult algorithms, statistical models and knowledge-based rules can be extracted from data, and the inherent parallelism speeds processing (Prieto, 1991). Another important advantage is the ANNs ability to generalize data and produce outputs for previously unseen inputs.

The most fundamental aspect of ANNs is their use of simple interconnected processing elements, which correspond loosely to neurons and synaptic connections in the brain. The strength of the connecting links determines the functionality of the ANN as a whole. The strength of each link is determined as the ANN learnability. The most common applications of ANNs involve regression and classification. Regression models attempt to estimate input-output transformation functions, while classification involves using the known inputs to determine class membership (Tsoukalas \& Uhrig, 1997).

There are three basic elements of an ANN model, which are illustrated in Figure 2: (1) a set of connecting links or synapses, each one is characterized by its weight. Specifically, an input signal to the synapse $j$ connected to neuron $k$ is multiplied by the synaptic weight $w_{k j}$; (2) an adder, which sums the input signals weighted with the respective synapses of the neuron, and (3) an activation function, which limits the permissible amplitude range of the output signal to some finite value. It defines the output of the neuron in terms of the induced local field, which is formed by the linear combiner output $u_{k}$ and the bias $b k$. This externally applied bias is used to increase or to low the net input of the activation function.

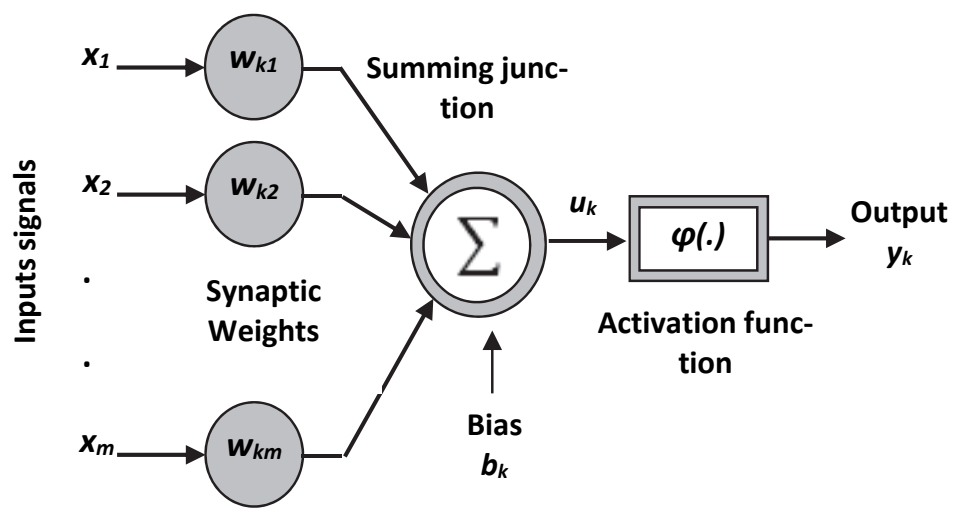

Fig. 2. Non-linear model of a neuron (Haykin, 1999)

The ANN's fundamental trait is the ability to learn and improve its performance. (Haykin, 1999) defines, as learning in the ANNs context, the process by which the free parameters of the ANN are adapted through stimulation provided by the environment where the network is embedded. Instead of following a set of rules, ANNs are able to learn underlying relationships from a collection of training examples. ANNs are usually classified into two main categories: recurrent networks, in which loops occur because 
of feedback connections, and feed-forward networks, in which the network structure has no loops. The choices of network architectures are intimately linked to the learning algorithm used in the training of the network. Multilayered, feed-forward, non-linear network models are utilized for general-purpose and generalization applications. These types of networks are commonly known as Multilayer Perceptions which have been successfully applied to solve diverse problems by training them in a supervised environment. The choices of network architectures are intimately linked to the learning algorithm used in the training of the network (Hachicha \& Ghorbel, 2012). Research that exploited ANN modeling in entrepreneurship is very rare and limited. Pittway et al., (2004) have used ANN to present systematic review of research linking the networking behavior of firms with their innovative capacity. In effectual context, neural network are indicated by Sarasvathy (2004) as a tool of both computer programming (including artificial intelligence) and human cognition (particularly human problem solving) developed together hand in hand. In the same context of effectuation and precisely in entrepreneurial uncertainty, Lin (2006) has verified research hypotheses of the influences on entrepreneurial-behavioral trends of environmental uncertainties. The author has also suggested decision styles and inter-organizational relations based on ANN model for both entrepreneurs and managers.

\section{Research procedure}

As mentioned in Fig. 3, the proposed approach is composed of three phases:

Phase 1: Effectual variables selection and prioritization

Phase 2: ANN model construction and validation

Phase 3: ANN model utilization

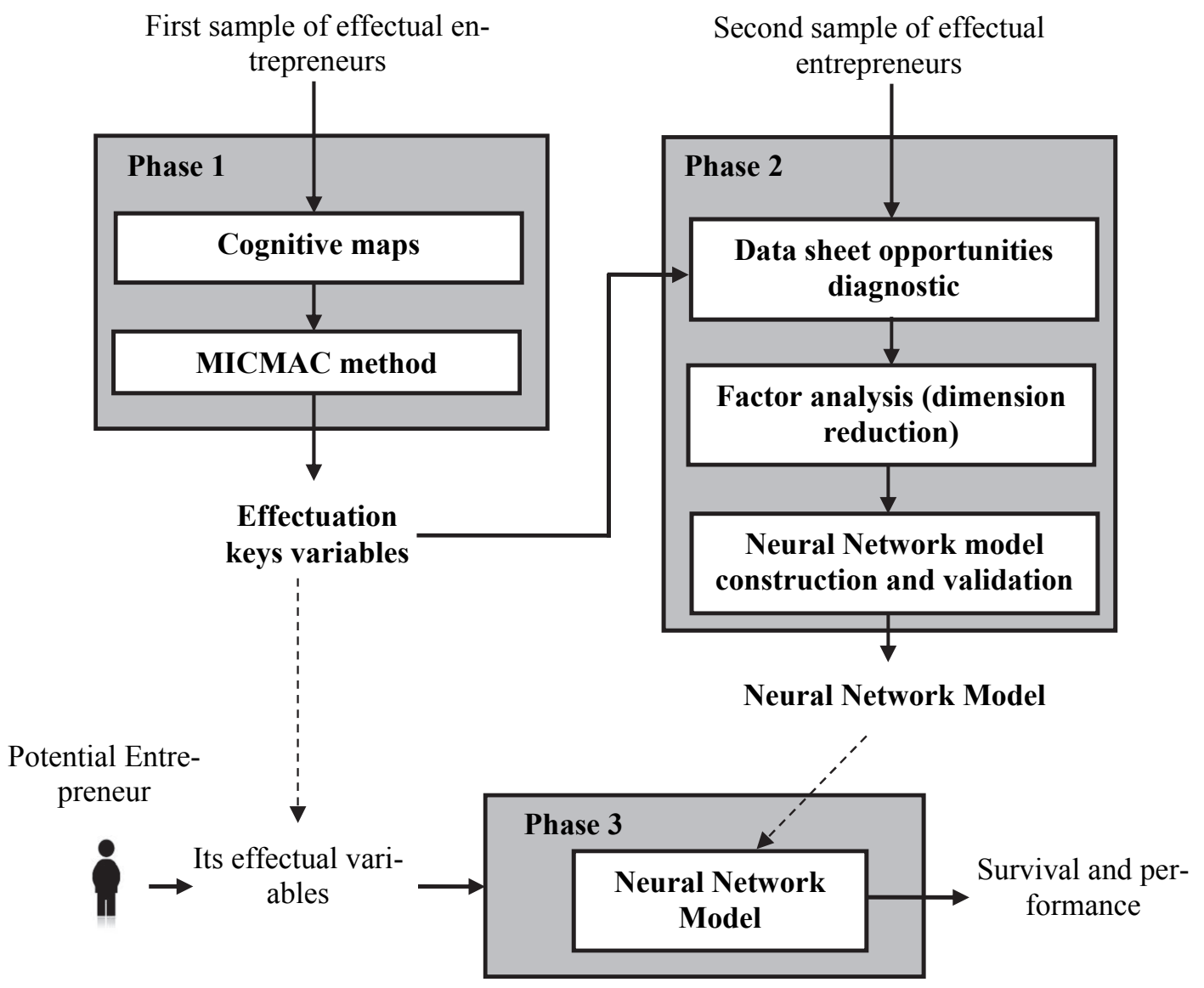

Fig. 3. Flow chart of the proposed approach 


\subsection{Effectual variables selection (Phase1)}

The first stage is composed of cognitive maps and MICMAC method. Generally the construction of the cognitive maps includes three main steps (Cossette, 2004). (1) Exploring the major idea and the entrepreneurial representations of entrepreneurs (2) A validation step of the reality of the explored idea from entrepreneur's reflection (3) Finally the analysis. For these reasons, a selected sample of entrepreneurs is interviewed using the grid systematic exploration in order to collect materials (concepts and variables). Each entrepreneur is encouraged to explore its own ideas or cognitive representations in relation to the logic used in the creation of his enterprise.

Secondly, we carry out MICMAC method. It is a structural analysis tool used in the identification of the most influential and dominating variables in the dynamic cognitive of the selected entrepreneurs. MICMAC method is applied separately to each entrepreneur. The objective is to identify the most influent and dominating effectual variables. The MICMAC analysis is applied using the computer software also called 'MICMAC' developed by a French computer innovation institute '3IE' (Institut d'Innovation Informatique pour l'Entreprise) under the supervision of its conceptual creators LIPSOR Prospective (foresight) Strategic and Organizational Research Laboratory.

MICMAC method structures the pooling of ideas. The structural analysis tends to list the key variables of a studied phenomenon via the adjacency matrix. The different variables and ideas identified for each entrepreneur (case) in the grid systematic exploration will be treated in cross matrix following a codification of the influence (1, low; 2, medium; 3, strong) of each variable in the act of creation of new business. Cross-matrix is the origin of the cognitive map's construction. The matrix is presented in the form of a table with $\mathrm{n}$ rows and $\mathrm{n}$ columns. Box of index $(\mathrm{i}, \mathrm{j})$ indicates the relationship between concept $\mathrm{i}$ and concept $\mathrm{j}$. The actors manipulate the key concepts and assign pairs of concepts depending on the nature and degree of proximity sensed between these concepts (Garoui \& Jarboui, 2012).

\subsection{ANN model construction and validation (Phase 2)}

Based on the keys variables emanating from the first phase, the second phase consist on building an ANN that interconnect entrepreneurial firms survival and performance (output) with effectuation key variables (inputs). For this reason, the phase 2 of the proposed approach is carried out in three steps, as mentioned in Fig. 3.

The first step is to develop a prototype of a questionnaire that aims to diagnose entrepreneurial opportunities from point of view of new business survival and performance (Moreau, 2007; Hernandez, 2001). This questionnaire is called "data sheet opportunities diagnostic" (see example in appendix 1). We tried to shell every selected key variable in the data sheet opportunities diagnostic by different questions emanate from the literature review. The second step of phase 2 is to apply factor analysis as a dimension reduction technique. Indeed, the number of key variables selected in the first phase may be very large (depending on context application). This number requires a reduction, for a better ANN model construction. The aim of the third step is to build and to validate the ANN model. The phase 2 will be more detailed in the application subsection.

\subsection{ANN model utilization (Phase 3)}

All over the world, nascent entrepreneur looks for the survival and the performance of created opportunities in the context of entrepreneurial activity. The entrepreneurial opportunity is the gravity center of the theory of effectuation's research. This opportunity is created, in an environment characterized by its uncertainty, by a talented or an expert entrepreneur. Entrepreneurship researches in different geographies, industries and contexts aim to develop and support entrepreneurial ventures. The objective 
of phase 3, is to apply the ANN model to gives the survival and the performance of a new venture for a nascent entrepreneur. In addition, it will allow him to identify weaknesses in their effectual process.

\section{Application to the Tunisian context}

According to the experts of entrepreneurship in Tunisia, it is necessary to understand how this phenomenon really works in this country (Nabli, 2010). Effectuation theory may well be a major contribution to study entrepreneurship in Tunisia from the point of view of its principles and its dynamic cycle. It is appropriate to focus on new topics and research perspectives of entrepreneurship in Tunisia by studying entrepreneurs as being compatible players with principles of effectuation's theory. To study the theory of effectuation in a Tunisian context, the proposed approach will be applied.

\subsection{Effectual variables selection (Phase1)}

Based on the principles of effectual logic, 12 effectual entrepreneurs from Tunisia are selected who shared effectuation principles. The selection criteria are: (1) Opportunity (2) Available means, and (3) partnerships. Those entrepreneurs are the origin of the development of the first phase of the proposed approach.

Table 1

The first sample of effectual entrepreneurs

\begin{tabular}{|c|c|c|c|c|}
\hline Name & Code & Opportunity & Available means & $\begin{array}{l}\text { Main effectuation variables and prin- } \\
\text { ciples }\end{array}$ \\
\hline Semi, G & E1 & $\begin{array}{l}\text { Industry of Ital- } \\
\text { ian marble }\end{array}$ & $\begin{array}{l}\text { Individual funds with signif- } \\
\text { icant help from family and } \\
\text { friends }\end{array}$ & $\begin{array}{l}\text { Expertise, innovation and operation } \\
\text { of the relational network. }\end{array}$ \\
\hline Abdjalil,B & $\mathrm{E} 2$ & $\begin{array}{l}\text { Diverse busi- } \\
\text { ness }\end{array}$ & $\begin{array}{l}\text { Its beginning is nothing, } \\
\text { Now he built a business em- } \\
\text { pire }\end{array}$ & $\begin{array}{c}\text { Two doctoral theses, Association } \\
\text { President, Business managers in Bel- } \\
\text { gium and Tunisia }\end{array}$ \\
\hline Abdrazek, G & E3 & Textile & $\begin{array}{l}\text { He got financial and tech- } \\
\text { nical help from his wife }\end{array}$ & Partnership with supplier from Dubai \\
\hline Absallem,H & E4 & Industry & $\begin{array}{l}\text { a friend }+ \text { her brother (they } \\
\text { have become associates) }\end{array}$ & $\begin{array}{c}\text { The garage of the home of the family } \\
\text { home was } \\
\text { the local of business }\end{array}$ \\
\hline Baligh,H & E5 & Service & $\begin{array}{l}\text { Funds collected from work } \\
\text { for } 2 \text { years in Libya }\end{array}$ & Innovative service with reduce prices \\
\hline Chokri, A & E6 & Service & He sold his wife's jewellery & $\begin{array}{l}\text { Exploitation of commercial expertise. } \\
\text { Partner research and commitment } \\
\text { (his son then his brother) }\end{array}$ \\
\hline Fathi, K & E7 & Wholesale & Help of sfaxian businessman & Affordable loss \\
\hline Habib, K & E8 & $\begin{array}{l}\text { food-processing } \\
\text { industry }\end{array}$ & Selling the family home & $\begin{array}{l}\text { Unexpected voyage to France led the } \\
\text { development of the project }\end{array}$ \\
\hline Lassad,K & E9 & Dairy firm & patrimony & customers have become associated \\
\hline Lotfi, G & $\mathrm{E} 10$ & Export-Import & $\begin{array}{l}\text { Cooperation with a Belgian } \\
\text { friend }\end{array}$ & $\begin{array}{l}\text { Concentration of the activity in Afri- } \\
\text { can countries }\end{array}$ \\
\hline Ridha,G & E11 & Wholesale & $\begin{array}{l}\text { Funds collected during his } \\
\text { work at Mr. Noureddine.K }\end{array}$ & $\begin{array}{c}\text { Partners commitment from Sfax and } \\
\text { Kasserine }\end{array}$ \\
\hline Slim, A & $\mathrm{E} 12$ & retail business & $\begin{array}{l}\text { Project financed by family } \\
\text { (essentially his sister) }\end{array}$ & $\begin{array}{l}\text { Firm starts with available means, the } \\
\text { commercial expertise and the cooper- } \\
\text { ation of the sister of M. Slim }\end{array}$ \\
\hline
\end{tabular}


Table 1 shows briefly the effectual variables description of each selected entrepreneurs. It should be noted that the totality of entrepreneurs have not accepted that their last names be published. The Centrality analysis that is based on the determination of the total weight of concepts available on our dependent variable shows that different variables proposed are being selected as factors that influence effectual entrepreneurial activity. However, it is interesting to classify these determinants according to their importance in the cognitive scheme of entrepreneurs in our sample. It is logical that the most active concept is one that has the highest total weight.

A cognitive maps and MICMAC method are successively applied to each of these selected entrepreneurs. In the following, the presentation is limited to the Lassad case which is coded by E9. Figure 4 shows the cognitive map of the case E9 using the grid systematic exploration. The aim of this map is to construct, from variables extracted during guided interview with this entrepreneur in order to analyze entrepreneur's opportunity representation.

The next step is to use MICMAC method. This method gives the total influence and dependence between their effectual variables. The weight of each variable denotes the sum of dependence and influence between variables. The variable which has the value of the largest weight is considered more important.

Table 2

Example MICMAC application (case E9)

\begin{tabular}{lcccc}
\hline \multicolumn{1}{c}{ Variable } & $\begin{array}{c}\text { Total influence be- } \\
\text { tween variables }\end{array}$ & $\begin{array}{c}\text { Total dependence be- } \\
\text { tween variables }\end{array}$ & Degree of connection & Weight (W) \\
\hline Stakeholders & 36 & 32 & 1.13 & 68 \\
Expertise & 36 & 32 & 1.13 & 68 \\
Control & 36 & 30 & 1.20 & 66 \\
Crazy patchwork & 35 & 27 & 1.30 & 62 \\
Uncertainty & 36 & 21 & 1.71 & 57 \\
Affordable loss & 24 & 30 & 0.80 & 54 \\
Opportunity & 24 & 29 & 0.83 & 53 \\
Available means & 22 & 30 & 0.73 & 52 \\
Bootstrapping & 14 & 30 & 0.47 & 44 \\
Business plan & 13 & 20 & 0.65 & 33 \\
\hline \multicolumn{1}{c}{ Total } & 356 & 356 & & \\
\hline
\end{tabular}

Consequently, as indicated in Table 2, the stakeholder concept, expertise variable, control variable have a large dominant total weight compared to other concepts. They are the most important variables for the success of entrepreneur Lassad (case E9).

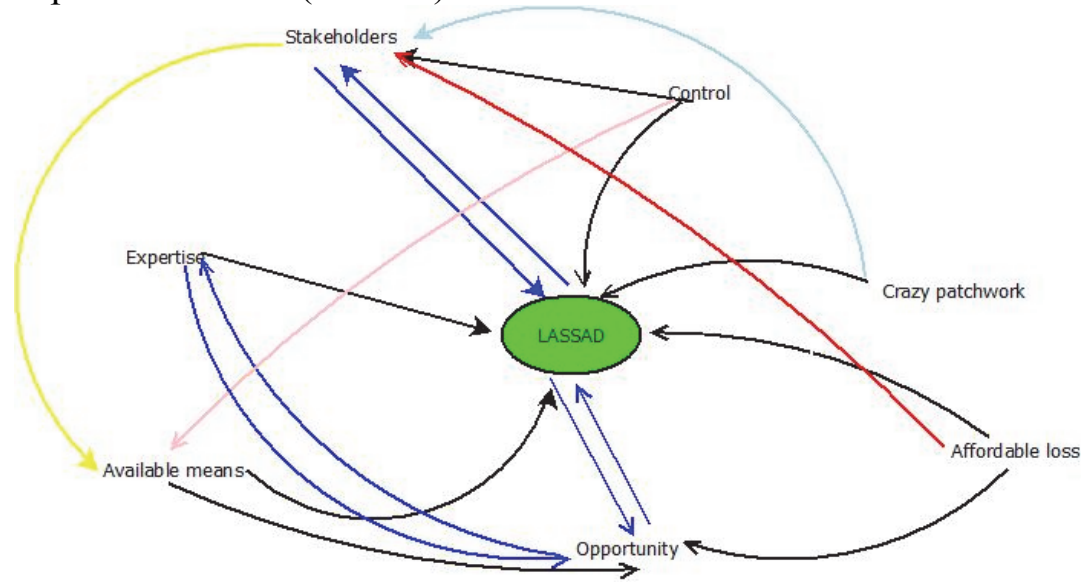

Fig. 4. The cognitive map of the entrepreneur E9 
The entrepreneur E9 always looks to improve his situation with stakeholders. Following to his three projects fail, E9 had financial difficulties, conflicts with competitors, customers and family. He decided to start his business again based on his network. The new case is agricultural; it is the center of expertise in the family of E9. For E9 expertise is not enough, this gentleman emphasizes the importance of stakeholder commitment in the emergence of business. Stakeholders are essential remedies face the uncertainty which is the origin of the failure of these projects. The procedure applied to E9, which is explained above, is also applied to others entrepreneurs.

\section{Table 3}

Cognitive concepts weight of effectuation variables

\begin{tabular}{|c|c|c|c|c|c|c|c|c|c|c|c|c|c|c|}
\hline & Effectual variables & E1 & E2 & E3 & E4 & E5 & E6 & E7 & E8 & E9 & E10 & E11 & E12 & Weight (W) \\
\hline 1 & Stakeholders & & & 31 & 21 & 35 & 22 & 27 & 26 & 68 & 14 & 28 & 17 & 289 \\
\hline 2 & Expertise & 32 & 43 & 29 & 25 & 33 & & 28 & 25 & 68 & 16 & 26 & 17 & 267 \\
\hline 3 & Opportunity & 36 & 36 & 33 & & 32 & 19 & 28 & 23 & 53 & & 27 & 20 & 235 \\
\hline 4 & Crazy Patchwork & & 36 & 35 & & 28 & & & 21 & 62 & 15 & & & 161 \\
\hline 5 & Affordable loss & 31 & 28 & 28 & & 29 & & 22 & 25 & 54 & & & & 158 \\
\hline 6 & Available Means & 37 & 29 & 29 & 24 & & & & 22 & 52 & 13 & & 17 & 157 \\
\hline 7 & Control & 34 & 43 & & & 35 & & 26 & & 66 & & 21 & & 148 \\
\hline 8 & Bootstrapping & 29 & & & 17 & 28 & 19 & & & 44 & & & & 108 \\
\hline 9 & Business plan & 15 & 25 & 21 & & 18 & 12 & & & 33 & & & 13 & 97 \\
\hline 10 & Contingency & 27 & 42 & & & & 16 & & & 55 & & 20 & & 91 \\
\hline 11 & Pragmatism & & 43 & & & & & 27 & & 52 & & & & 79 \\
\hline 12 & Uncertainty & & 40 & & & & & & & 57 & & & & 57 \\
\hline 13 & Network & & & & 22 & & & & & & & & & 22 \\
\hline
\end{tabular}

The Table 3 shows the results of the first phase of the proposed approach application in an ascending order. According to Table 3, we note that the selected entrepreneurs share in the creation of their new business the effectuation theory's keys variables. Stakeholders, expertise, opportunity and crazy patchwork are the most influent and dominating variables in effectual entrepreneur cognition.

ANN model construction and validation (Phase 2)

\subsection{Data sheet opportunities diagnostic}

Based on the keys variables emanate from the phase 1, a questionnaire is developed to diagnose entrepreneurial opportunities from point of view of new business survival and performance. "Survival" and "performance" are largely used in literature (Moreau, 2007; Hernandez, 2001). After the development of the questionnaire called "data sheet opportunities diagnostic" (appendix 1) sixty seven cases are collected. Nine variables are selected from the whole variables identified in the cognitive mapping study. Each selected variable is shelled in the data sheet opportunities diagnostic by different questions emanate from the literature review. For more detail, reader can consult appendix. Response elements for every question are fixed by Likert scale.

\subsection{Factor analysis (dimension reduction)}

Capture different questionnaires for 67 entrepreneurs (second sample) has raised a mass of important data including a large number of variables. A dimension reduction tool is necessary to overcome this technical problem. The most convenient method is factor analysis. The principal component analysis (PCA) method is one of the popular tools used to reduce the number of factors. The method is based on a linear combination of factors projection. It allows a more concise data representation.

As mentioned in Table 4, the PCA method reduces the number of variables from 13 to 7. Seven new variables (factors) are performed named F1, F2, F3, F4, F5, F6, and F7. 
Table 4

Total variance using factorial analysis

\begin{tabular}{|c|c|c|c|c|c|c|}
\hline \multirow{2}{*}{ Component } & \multicolumn{3}{|c|}{ Initial eigenvalues } & \multicolumn{3}{|c|}{ Extraction Sums of squares of the factors identified } \\
\hline & Total & $\%$ of the variance & Cumulative $\%$ & Total & $\%$ of the variance & Cumulative $\%$ \\
\hline F1 & 3.378 & 25.981 & 25.981 & 3.378 & 25.981 & 25.981 \\
\hline $\mathbf{F 2}$ & 1.611 & 12.394 & 38.375 & 1.611 & 12.394 & 38.375 \\
\hline F3 & 1.560 & 11.998 & 50.374 & 1.560 & 11.998 & 50.374 \\
\hline F4 & 1.288 & 9.906 & 60.280 & 1.288 & 9.906 & 60.280 \\
\hline F5 & 1.156 & 8.890 & 69.170 & 1.156 & 8.890 & 69.170 \\
\hline F6 & 1.014 & 7.800 & 76.970 & 1.014 & 7.800 & 76.970 \\
\hline F7 & .750 & 5.771 & 82.742 & .750 & 5.771 & 82.742 \\
\hline F8 & .564 & 4.338 & 87.079 & & & \\
\hline F9 & .428 & 3.289 & 90.368 & & & \\
\hline F10 & .401 & 3.084 & 93.453 & & & \\
\hline F11 & .354 & 2.724 & 96.177 & & & \\
\hline F12 & .282 & 2.172 & 98.349 & & & \\
\hline F13 & .215 & 1.651 & 100.000 & & & \\
\hline
\end{tabular}

\subsection{ANN model construction}

The ANN model makes the connection of the outputs (Survival and Performance) and the transformed inputs F1, F2, F3, F4, F5, F6, and F7. As indicated in Figure 5, the configuration of the neural network second-order linear regression model has 7 input nodes F1, F2, F3, F4, F5, F6, and F7, two output node (Survival and Performance), and one hidden layers. The second order polynomial model allows characterizing the influence of squares cross inputs. The total number of available sample size (observations) is 67. The first step is about how separates the available samples into two groups as: training and testing samples, which are used for the model training and for the model fitness validation, respectively. According to Yang et al. (2005), this step is commonly realized based on many tested scenarios to choice the optimal ratios between the training sample size and the testing sample size. This step gets even more complicated if there is a lack of available sample size. In this study, the number of sample size is very adequate and the problem of determining the optimal ratios does not arise. Thus, 12 testing samples (Table 5) are used for the validation of the fitness model. It is important to randomly choice these testing samples.

Table 5

Neural network model validation

\begin{tabular}{|c|c|c|c|c|c|c|c|c|c|c|}
\hline \multirow[b]{2}{*}{ Name } & \multicolumn{2}{|c|}{ Observed } & \multicolumn{4}{|c|}{ Linear model order 1} & \multicolumn{4}{|c|}{ Linear model order 2} \\
\hline & $\mathrm{S}$ & $\mathrm{P}$ & $\mathrm{S}$ & $\mathrm{P}$ & S. error $(\%)$ & $\begin{array}{l}\text { P. Error } \\
(\%)\end{array}$ & $\mathrm{S}$ & $\mathrm{P}$ & $\begin{array}{c}\text { S. error } \\
(\%)\end{array}$ & P. Error $(\%)$ \\
\hline 3 & 3 & 4 & 2.788 & 3.655 & $7.1 \%$ & $8.6 \%$ & 2.845 & 3.761 & $5.2 \%$ & $6.0 \%$ \\
\hline 4 & 2 & 3 & 2.609 & 2.927 & $30.5 \%$ & $2.4 \%$ & 2.148 & 3.202 & $7.4 \%$ & $6.7 \%$ \\
\hline 11 & 4 & 3 & 2.615 & 2.122 & $34.6 \%$ & $29.3 \%$ & 4.229 & 2.785 & $5.7 \%$ & $7.2 \%$ \\
\hline 22 & 2 & 3 & 2.555 & 2.716 & $27.8 \%$ & $9.5 \%$ & 2.035 & 2.954 & $1.8 \%$ & $1.5 \%$ \\
\hline 23 & 3 & 4 & 3.157 & 3.976 & $5.2 \%$ & $0.6 \%$ & 3.173 & 3.704 & $5.8 \%$ & $7.4 \%$ \\
\hline 32 & 3 & 2 & 3.041 & 2.092 & $1.4 \%$ & $4.6 \%$ & 2.978 & 2.081 & $0.7 \%$ & $4.1 \%$ \\
\hline 38 & 4 & 3 & 2.343 & 2.108 & $41.4 \%$ & $29.7 \%$ & 4.347 & 2.969 & $8.7 \%$ & $1.0 \%$ \\
\hline 46 & 2 & 3 & 3.004 & 2.981 & $50.2 \%$ & $0.6 \%$ & 2.101 & 2.947 & $5.1 \%$ & $1.8 \%$ \\
\hline 47 & 3 & 2 & 2.92 & 2.251 & $2.7 \%$ & $12.6 \%$ & 3.287 & 1.854 & $9.6 \%$ & $7.3 \%$ \\
\hline 54 & 3 & 3 & 2.635 & 3.141 & $12.2 \%$ & $4.7 \%$ & 2.731 & 2.966 & $9.0 \%$ & $1.1 \%$ \\
\hline 55 & 3 & 4 & 3.326 & 4.162 & $10.9 \%$ & $4.1 \%$ & 2.961 & 4.108 & $1.3 \%$ & $2.7 \%$ \\
\hline 59 & 3 & 4 & 3.483 & 3.349 & $16.1 \%$ & $16.3 \%$ & 3.059 & 3.821 & $2.0 \%$ & $4.5 \%$ \\
\hline
\end{tabular}

S: Survival

P: Performance

A commercial software package, (CNeuro One Standard 6.12 was adopted for the ANN modelling and prediction. The used software includes two main modules: (1) The Neuro One module is the tool which 
allows the loading and the pre-treatment of data, the selection of the descriptors, the building of polynomial linear models and of most frequent neural networks, the supervision and analysis of the learning results, charts and statistic tables editing, results storage, and (2) the Neuro Fit module is a tool which simulates in direct mode, reverse mode, input compensation mode, desirability about outputs of the models that have been saved from the Neuro One module.

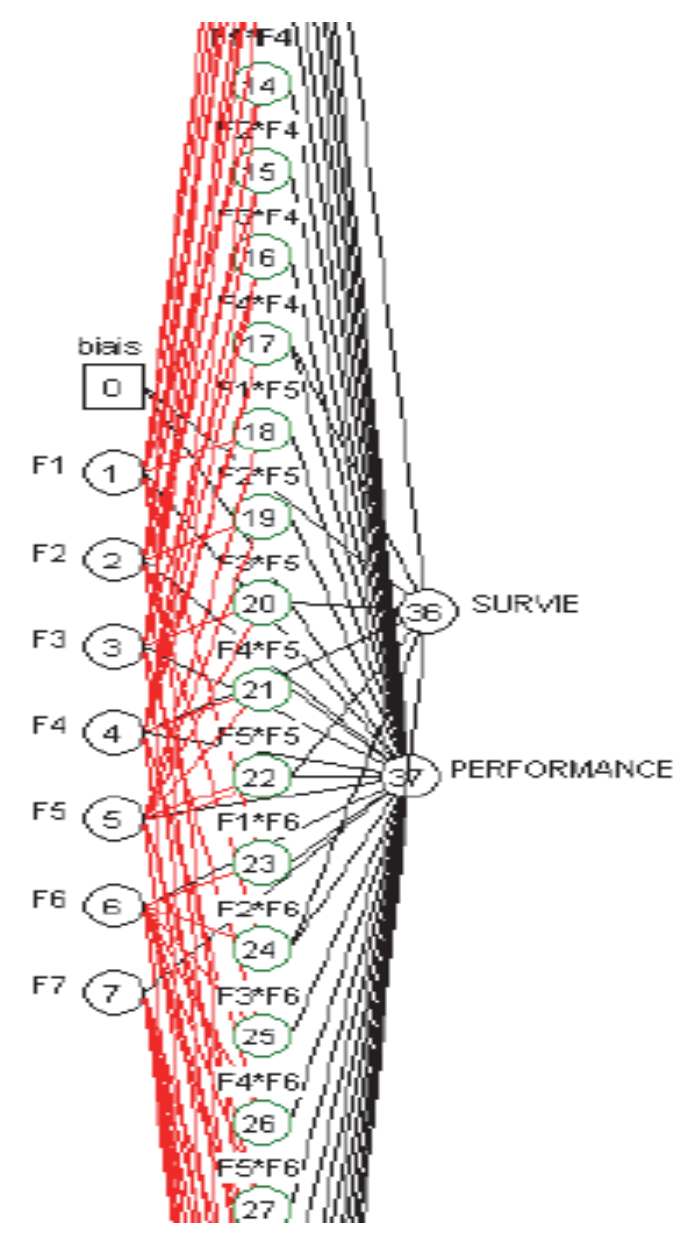

Fig. 5. Neural network structure

\subsection{ANN model validation}

ANN architecture can be defined as the determination of the number of input, output, and hidden neurons, and the number of hidden layers. Two ANN models were tested. The first model is a polynomial model of order 1 . The second model is polynomial of order 2. Both models are linear models in their settings. However, the second model is a non-linear model towards the inputs variables, but linear towards the coefficients.

It should be noted that the polynomial models of order greater than 2 are impossible to carry out because data are not enough available. Following the results shown in Table 5, the non-linear 2nd order model is founded more effective. The 2 nd order model gives a reduced training cost compared to the linear model of order 1. 
Table 6

ANN models fitness

\begin{tabular}{cccc}
\hline Model Type & Training cost & Validation \\
& & Average error \% & Max error \% \\
\hline First order model & 1.089 & 15.1 & 50.2 \\
2nd order model & 0.732 & 4.7 & 9.6 \\
\hline
\end{tabular}

Table 6 shows the average error is $4.7 \%$. The maximum error not exceeds $9.6 \%$. The cost of learning is a function of the difference between the model output and examples presented calculated on the data of the training set.

\subsection{ANN model utilization (Phase 3)}

To access the ANN method which aims to build a conception emergence model of the survival and the performance of entrepreneurial opportunities, we have prepared data sheet for Opportunities. The ANN model can help potential entrepreneurs to have an emerging idea about survival and performance of their business projects. To study opportunities by an ANN model, the entrepreneur is called to answer the questionnaire developed (data sheet ) to perform estimation of F1, F2, F3, F4, F5, F6 and F7 factors which will be introduced in the performed ANN model. For each evaluated opportunity, two criteria are to be recorded/ noted:

1 - If the modeling arises from Table 3 (Neural network model validation) has given good results, the entrepreneur should be supported by the various support organizations. The opportunities are not always viable, because the environment and the creation cycle are dynamic/ are not static. Entrepreneurial action is a source of learning and originates from the entrepreneur himself. The potential entrepreneur can become an expert entrepreneur using a process that links reflection, decision and action.

2 - If the modeling arises from Table 3 (Neural network model validation) has provided negative results, the opportunity should be reconfigured in response to environmental characteristics. First, the entrepreneur may participate to trainings which are specialized in establishment and development of opportunities. Besides, the role of coaches and mentors is essential in improving the learning and expertise among the potential entrepreneur. In that case, the entrepreneur may base its entrepreneurial process on oriented action, by concentrating on the available resources and the reasoning in affordable loss, which constitute a key idea of effectual logic.

\section{Conclusion}

This paper has aimed to propose an approach for studying effectual entrepreneurial opportunities with the majority of effectual theory variables. The proposed mixed approach was carried out in three phases. In the first phase, entrepreneur's effectuation variables were selected via a cognitive map and MICMAC method for each sample entrepreneur. In the second phase, an Artificial Neural Network (ANN)based model has been performed to highlight the emergence of potential entrepreneur's conception which rely effectuation key variables with survival and performance. Finally, in the third phase the ANN model was applied to analyze opportunity success for a potential nascent entrepreneur based on its effectuation variables. As a validation purpose, the proposed approach was applied to a virgin context such as Tunisian country. Many confirmations of the previous literature and interesting findings have been concluded. Principally, the results of the proposed approach are essential to diagnose and to appraise entrepreneurial opportunities for each potential Tunisian entrepreneur. 
Generally, all of the entrepreneurship researches have been concentrated on the entrepreneurial discovery approach. In such approach, entrepreneurial activity is based on the identification, evaluation and exploitation of opportunities process. The entrepreneur who discovers opportunities is a risk taker, vigilant, and has the social flexibility to identify an opportunity. Contrary to this view, effectuation theory exposes more sophisticated principles of entrepreneurial activity which include variety of dimensions such as cognition, resources, partnerships, monitoring and contingency. The results of this research are compatible with the effectuation's principles. They also provide perspectives for entrepreneurship research in the context of effectual logic.

Researches on the theory of effectuation are living a remarkable increase. Generally, each research focuses on a specific theme or a determined variable. In this research, we have tried to decorticate the theory of effectuation by analyzing its principles and by understanding its dynamic cycle. Results of our research (which aims the identification and formalization of effectuation in the Tunisian context) obtained through cognitive mapping and neural networks showed that the Tunisian entrepreneurs think and act in an effectual way. The study carried via cognitive map and MICMAC method has verified that the entrepreneurs in the sample share and use exclusively the effectuation logic in the creation of their entrepreneurial firms. In their cognitive dynamics, Tunisian entrepreneurs are characterized by a preponderance of effectual variables. Stakeholders, expertise, crazy patchwork, the reasoning in affordable loss, available resources, control and bootstrapping are extracted the most powerful and dominant variables.

This research contributes to the entrepreneurial field in several registers. From a theoretical point, we contribute in this research to a better understanding of entrepreneurial firm's creation in Tunisia. Remaining within the framework of constructed opportunity, specific themes have been developed in an effectual context that promotes the concept of co-creation. Furthermore, we make enrichments to the way of theorizing and practicing entrepreneurship, avoiding the idea of mythic entrepreneur who owns exclusively success factors. In effectuation, any person may become an entrepreneur in his own way.

At the end of this work, a transfer of effectuation from its original development framework (United States) to a Tunisian context has been validated by an empirical study based on the proposed approach, which provides a better understanding of how Tunisian entrepreneurs think and act. In effectuation, neural networks are used for the first time in our research. In addition, our contribution on a practical level resides in the fusion between cognitive mapping and neural networks. Thus, the development of an evaluation sheet of potential entrepreneurial opportunities may have direct implication in the entrepreneurs and stakeholders engagement for setting up entrepreneurial projects.

Although, considerable attention was given to the effectual opportunities in Tunisia. Some limitations still exist. It is interesting to develop the model with the entrepreneurship's organizations support in Tunisia to improve the modeling process. Secondly, the effectual logic can be studied in a transversal and deeper way across the different regions and on the basis of a time scale. So we gain better understanding of the emergence of entrepreneur's conception. These entrepreneurs, we are talking about, were potential entrepreneurs and then became expert entrepreneurs.

\section{References}

Alvarez, S. A., \& Barney, J. B. (2010). Entrepreneurship and epistemology: The philosophical underpinnings of the study of entrepreneurial opportunities. The Academy of Management Annals, 4(1), 557-583.

Axelrod, R. (1976). Structure of Decision: the Cognitive Maps of Political Elites, Princeton, N J: Princeton University Press.

Bertolini, P., \& Giovannetti, E. (2006). Industrial districts and internationalization: the case of the agrifood industry in Modena, Italy. Entrepreneurship and regional development, 18(4), 279-304. 
Bootz, J. P., \& Monti, R. (2008). Proposition d'une typologie des démarches de prospective participative pour les entreprises. Trois cas illustratifs: EDF R $\alpha \mathrm{D}$, AXA France et BASF Agro. Management \& Avenir, 5, 114-131.

Chandler, G. N., DeTienne, D. R., McKelvie, A., \& Mumford, T. V. (2011). Causation and effectuation processes: A validation study. Journal of business venturing, 26(3), 375-390.

Cossette, P. (2004). L'organisation: une perspective cognitiviste. Presses Université Laval.

Creswell, J. W., Plano Clark, V. L., Gutmann, M. L., \& Hanson, W. E. (2003). Advanced mixed methods research designs. Handbook of mixed methods in social and behavioral research, 209-240.

Dew, N., \& Sarasvathy, S. D. (2007). Innovations, stakeholders \& entrepreneurship. Journal of Business Ethics, 74(3), 267-283.

Dew, N., Read, S., Sarasvathy, S. D., \& Wiltbank, R. (2009). Effectual versus predictive logics in entrepreneurial decision-making: Differences between experts and novices. Journal of business venturing, 24(4), 287-309.

Eden, C. (1992). On the nature of cognitive maps. Journal of management studies, 29(3), 261-265.

Fuellhart, K. G., \& Glasmeier, A. K. (2003). Acquisition, assessment and use of business information by small-and medium-sized businesses: a demand perspective. Entrepreneurship \& Regional Development, 15(3), 229-252.

Garoui, N and A. Jarboui. (2012). Cognitive approach of corporate governance. A visualization test of mental models with cognitive mapping technique. The Romanian Economic Journal, 43, 61-96.

Gartner, W. B. (1988). Who is an entrepreneur is the wrong question. American Journal of Small Business, 4(12), 11-32.

Faiez, G., \& Younes, B. (2012). A cognitive approach for analyzing the influence of effectual network on entrepreneurs actions. Interdisciplinary Journal of Contemporary Research in Business, 3(9), 1409-1431.

Ghorbel, F., \& Boujelbène, Y. (2013). A comprehensive literature review of effectuation theory from 1999 to 2011. International Journal of Entrepreneurial Venturing, 5(2), 168-194.

Hachicha, W., \& Ghorbel, A. (2012). A survey of control-chart pattern-recognition literature (19912010) based on a new conceptual classification scheme. Computers \& Industrial Engineering, 63(1), 204-222.

Hansen, D. J., Shrader, R., \& Monllor, J. (2011). Defragmenting definitions of entrepreneurial opportunity. Journal of Small Business Management, 49(2), 283-304.

Haykin, S. (1999). Neural Networks, Prentice-Hall, New Jersey, NY.

Hernandez, E.M. (2001). L'entrepreneuriat: approche théorique, Editions L'Harmattan.

Jack, S. L. (2005). The role, use and activation of strong and weak network ties: A qualitative analysis. Journal of management studies, 42(6), 1233-1259.

Jack, S. L., \& Anderson, A. R. (2002). The effects of embeddedness on the entrepreneurial process. Journal of business Venturing, 17(5), 467-487.

Khiari, S., Khelil, N., Zouaoui, M., \& Smida, A. (2011). Représentations que se font les dirigeants de la performance de leur jeune entreprise technologique innovante (JETI). Approche exploratoire basée sur la cartographie cognitive. Revue de l'Entrepreneuriat, 10(3), 33-65.

Kraaijenbrink, J. (2012). Chapter 13 The Nature of the Entrepreneurial Process: Causation, Effectuation, and Pragmatism. In New Technology-Based Firms in the New Millennium (pp. 187-199). Emerald Group Publishing Limited.

Krueger, N. F. (2005). The cognitive psychology of entrepreneurship. Handbook of entrepreneurship research, 105-140.

Lendaris, G.B. (1980). Structural Modeling-A Tutorial Guide”, IEEE-SMC, 10, no.2: 807-840.

Lin, W. B. (2006). A comparative study on the trends of entrepreneurial behaviors of enterprises in different strategies: Application of the social cognition theory. Expert Systems with Applications, 31(2), 207-220.

Lumpkin, G. T., \& Lichtenstein, B. B. (2005). The role of organizational learning in the opportunityrecognition process. Entrepreneurship theory and practice, 29(4), 451-472. 
Molina-Azorín, J. F., López-Gamero, M. D., Pereira-Moliner, J., \& Pertusa-Ortega, E. M. (2012). Mixed methods studies in entrepreneurship research: Applications and contributions. Entrepreneurship \& Regional Development, 24(5-6), 425-456.

Moreau, R. (2000). La réussite entrepreneuriale: une proposition pour un modèle explicatif général. Gestion, 24(3), 45-62.

Nabli, R. (2008). Les entrepreneurs tunisiens: la difficile émergence d'un nouvel acteur social. Editions L'Harmattan.

Anis, O., \& Mohamed, F. (2012). How entrepreneurs identify opportunities and access to external financing in Tunisian's micro-enterprises?. African Journal of Business Management, 6(12), 4635.

Omri, A., \& Frikha, M. (2011). Failure factors in Tunisian micro-enterprises: Introspection through cognitive mapping. Journal of Small Business \& Entrepreneurship, 24(4), 493-512.

Palich, L. E., \& Bagby, D. R. (1995). Using cognitive theory to explain entrepreneurial risk-taking: Challenging conventional wisdom. Journal of business venturing, 10(6), 425-438.

Parrilli, M. D. (2009). Collective efficiency, policy inducement and social embeddedness: Drivers for the development of industrial districts. Entrepreneurship and Regional Development, 21(1), 1-24.

Pittaway, L., Robertson, M., Munir, K., Denyer, D., \& Neely, A. (2004). Networking and innovation: a systematic review of the evidence. International journal of management reviews, 5(3-4), 137-168.

Prieto, A. (1991). Artificial Neural Networks, International Workshop. IWANN '91, Granada, Spain, Proceedings in Lecture Notes in Computer Science, Springer.

Read, S., Sarasvathy, S., Dew, N., Wiltbank, R., \& Ohlsson, A.V. (2011). Effectual Entrepreneurship. Routeldge, Taylor and Francis, London.

Rosa, P., \& Dawson, A. (2006). Gender and the commercialization of university science: academic founders of spinout companies. Entrepreneurship and Regional Development, 18(4), 341-366.

Sarasvathy, S. D. (2001). Causation and effectuation: Toward a theoretical shift from economic inevitability to entrepreneurial contingency. Academy of management Review, 26(2), 243-263.

Sarasvathy, S. D. (2004). Making it happen: Beyond theories of the firm to theories of firm design. Entrepreneurship Theory and Practice, 28(6), 519-531.

Sarasvathy, S. (2008). Effectuation elements of entrepreneurial expertise. New Horizons in Entrepreneurship Series.

Sarasvathy, S. D., \& Venkataraman, S. (2011). Entrepreneurship as method: Open questions for an entrepreneurial future. Entrepreneurship theory and practice, 35(1), 113-135.

Shane, S. (2003). A General Theory of Entrepreneurship: The Individual-Opportunity Nexus. Cheltenham, UK: Edward Elgar.

Shane, S., \& Venkataraman, S. (2000). The promise of entrepreneurship as a field of research. Academy of Management Review, 25(1), 217-226.

Shane, S., \& Khurana, R. (2003). Bringing individuals back in: the effects of career experience on new firm founding. Industrial and Corporate Change, 12(3), 519-543.

Silberzahn, P. (2013). Effectuation : Les principes de l'action entrepreneuriale. Amazon Media, $120 \mathrm{p}$.

Tolman E.C. (1948). Cognitive maps in rats and men. Psychological Review, 55(4), 189-208.

Tsoukalas, L.H and R.E. Uhrig. 1997. Fuzzy and neural approaches in engineering, New York: Wiley. Wiltbank, R., Read, S., Dew, N., \& Sarasvathy, S. D. (2009). Prediction and control under uncertainty: Outcomes in angel investing. Journal of Business Venturing, 24(2), 116-133.

Yang, T., Tsai, T. N., \& Yeh, J. (2005). A neural network-based prediction model for fine pitch stencilprinting quality in surface mount assembly. Engineering Applications of Artificial Intelligence, 18(3), 335-341.

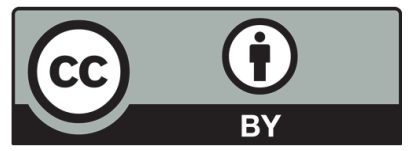

(C) 2017 by the authors; licensee Growing Science, Canada. This is an open access article distributed under the terms and conditions of the Creative Commons Attribution (CC-BY) license (http://creativecommons.org/licenses/by/4.0/). 